\title{
Políticas Públicas Baseadas em Evidências: uma avaliação crítica ${ }^{1}$
}

Maurício Mota Saboya Pinheiro²

There is nothing a government hates more than to be well-informed; for it makes the process of arriving at decisions much more complicated and difficult.

John Maynard Keynes

\section{INTRODUÇÃO}

O objetivo deste artigo é elucidar o conceito de evidência, que está no centro da abordagem das políticas públicas baseadas em evidências (PPBEs). Uma caracterização tradicional de PPBEs prescreve que "iniciativas de políticas devem ser apoiadas por evidências de pesquisas e as políticas apresentadas em bases tentativas devem ser avaliadas do modo mais rigoroso possível” (Plewis, 2000, p. 96). Ou ainda: PPBEs são uma abordagem que "ajuda na tomada de decisões bem informadas em políticas, programas e projetos públicos, colocando as melhores evidências de pesquisas disponíveis no coração do desenvolvimento e implementação das políticas públicas" (Davies, 2004, p. 3). Em ambas as citaçôes, as evidências são referidas como científicas, de caráter empírico, na área de política em questão. ${ }^{3}$

Outras conceituaçóes procuram ampliar o âmbito de aplicação das PPBEs ao conjunto das políticas públicas. Por exemplo, Nutley (2003, p. 4) caracteriza essa abordagem como "um processo em que a evidência [científica] pode e deve competir com outras formas de conhecimento e outros interesses" na tomada de decisóes dos agentes das políticas públicas. Contudo, a abertura para "outras formas de conhecimentos e interesses" agrava os problemas conceituais. Já que não estamos falando apenas de evidências científicas, como se definiriam, então, as informaçóes usadas nas açóes e decisóes de policymakers e outros atores interessados (stakeholders)? Esta pergunta resume o problema deste artigo.

Ao tentarem conceituar evidência, os estudos em geral "ou se limitam a contextos bem específicos, ou propóem caracterizaçóes muito gerais” (Pinheiro, 2020, p. 33). Por isso o problema conceitual persiste, levando vários autores (por exemplo, Oliver et al., 2014) a demandarem uma definição clara de "evidência", como uma espécie de propedêutica ao estudo das PPBEs. Porém, há razóes para crer que essa estratégia seja equivocada, pois o conceito de evidência é intrinsecamente vago e multidimensional,

1. DOI: http://dx.doi.org/10.38116/bapi24art1

2. Técnico de planejamento e pesquisa na Diretoria de Estudos e Políticas do Estado, das Instituições e da Democracia (Diest) do Ipea. 3. Neste artigo, entendemos por evidências científicas os conhecimentos produzidos a partir de métodos sistematizados e reprodutíveis, podendo abranger os seguintes itens (lista não exaustiva): i) identificação precisa de um problema de pesquisa, com variáveis dependentes e independentes bem delimitadas; ii) revisão da literatura acadêmica sobre o assunto; iii) coleta sistemática de dados e informações; iv) tratamento dos dados e informações com métodos quantitativos ou qualitativos rigorosos; v) discussão detalhada dos resultados; vi) publicação dos resultados em periódicos científicos; e vii) publicação em periódicos de universidades ou institutos de pesquisa. 
não se prestando a uma definição exata. ${ }^{4}$ Isso ocorre porque o conceito se aplica naturalmente a coisas pertencentes a ontologias muito distintas (fatos do mundo, fenômenos psicológicos, regras de linguagem etc.). Sem embargo, isso não significa que ele seja inanalisável de um ponto de vista racional, tampouco que seja inútil para as políticas públicas. Significa apenas que a análise do conceito de evidência carece de um método, com base em critérios moderados, razoáveis e pragmáticos.

A fim de cobrir, ao menos em parte, a lacuna metodológica apontada no parágrafo anterior, este texto se divide em cinco seções, contando com esta introdução e as considerações finais. A seção 2 propóe um método de elucidação para o conceito de evidência. A seção 3 explicita os pressupostos epistemológicos de um modelo (dito "moderado") acerca dos processos decisórios dos atores envolvidos em políticas públicas. Por fim, a seção 4 provê uma visão panorâmica da estrutura da ação (decisão) dos referidos atores e delimita o pano de fundo dessa ação numa moldura contextual.

\section{MÉTODO DE ELUCIDAÇÃO CONCEITUAL}

$\mathrm{Na}$ literatura especializada, não há uma caracterização sistemática das evidências usadas em políticas públicas. Tampouco parece haver qualquer convergência em relação a tipos, usos, fins, estruturas, enfim, as formas mais básicas da suposta realidade designada pelo termo "evidência". Diante disso, propóe-se um método de clarificação conceitual com os seguintes passos: i) mostrar a evoluçáo histórica do conceito de evidência, na abordagem das PPBEs; ii) articular os pressupostos epistemológicos dessa abordagem; e iii) fornecer uma visão panorâmica do "terreno conceitual" das evidências, com ênfase em seus contextos de uso em políticas públicas.

A importância da história para a análise de um conceito repousa simplesmente em que ele é usado no espaço e no tempo. O desdobramento histórico da aplicação de um conceito revela, portanto, aspectos importantes deste. Por isso, a recuperaçáo historial das PPBEs, ainda que de forma aproximativa e incompleta, é um passo importante no esclarecimento do conceito de evidência.

Como abordagem teórica, as PPBEs floresceram em fins dos anos 1990, no Reino Unido, com a subida ao poder do Partido Trabalhista e do gabinete chefiado por Tony Blair. ${ }^{5}$ Não obstante, as condiçôes de seu surgimento histórico incluem vários outros fenômenos e processos, tais como: i) o desenvolvimento das disciplinas e práticas de análise, avaliação e monitoramento de políticas públicas, nos Estados Unidos, a partir dos anos $1950 ;^{6}$ ii) a chamada revolução da informática

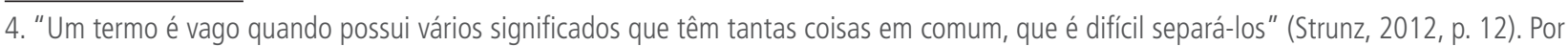
sua vez, por "multidimensionalidade", entende-se aqui a característica de que os vários e indefinidamente numerosos aspectos do conceito não se prestam a uma única "métrica" ou "sistema de coordenadas" em que suas regras de aplicação possam ser usadas. Por exemplo, pode-se dizer que a linguagem por meio da qual se expressam fatos, fenômenos e processos físicos não está no mesmo espaço lógico da linguagem "mentalista", usada para descrever estados mentais privados. Portanto, o conceito de linguagem seria multidimensional, no sentido dado neste artigo. Pode-se dizer também que o conceito de felicidade humana é multidimensional, pois os inúmeros aspectos que podem caracterizar uma pessoa feliz (renda, autoestima, educação, saúde, proteção social, convivência comunitária e familiar etc.) só podem ser avaliados com base em múltiplos critérios e "escalas". Sobre esses conceitos, ver Pinheiro (2020, p. 8).

5. Ver o documento oficial intitulado Modernising government (United Kingdom, 1999), que pode ser considerado o "manifesto fundador" da moderna abordagem das PPBEs.

6. Shadish Junior, Cook e Leviton (1995, p. 22) detectam um desenvolvimento das teorias e práticas de avaliação de programas sociais nos Estados Unidos a partir dos anos 1960, quando um aumento sem precedentes dos gastos públicos com programas de combate à pobreza sobretudo nas áreas de educação, renda mínima, habitação, saúde e justiça criminal - gerou uma demanda de vários setores sociais e políticos para a avaliação desses programas. Consequentemente, tiveram de ser desenvolvidos novos métodos, carreiras profissionais, fontes de informação, instrumentos, técnicas e teorias voltadas para a avaliação de programas públicos. Por sua vez, Worthen, Fitzpatrick e Sanders (2004, p. 64) mencionam o papel pioneiro da Lei Educacional de Defesa Nacional, de 1958, como fomentadora de uma grande onda de avaliação de programas educacionais nos Estados Unidos. 
(anos 1980), que colocou à disposição dos policymakers uma enorme massa de informaçóes com potencial de uso nas políticas públicas; iii) a filosofia do new public management (NPM) (anos 1980), cujos princípios enfatizavam, entre outras coisas, a eficiência, a relação custo-benefício, o foco na entrega de serviços públicos ao cidadão-contribuinte-usuário, a fixação de metas, o controle, monitoramento e acompanhamento de desempenhos e resultados; e iv) o movimento da medicina baseada em evidências (MBE), que floresceu com vigor em solo norte-americano em princípios dos anos 1980. A MBE preconizava a tomada de decisóes médicas com base em resultados de pesquisas científicas. Com o seu sucesso na melhoria da saúde humana, a MBE passa a ser uma espécie de modelo inspirador para as PPBEs.

Com o concurso dos fatores históricos citados no parágrafo anterior, as evidências científicas em políticas públicas são cada vez mais assumidas como instrumentos de racionalização de processos decisórios em políticas públicas. Esse significado, contudo, não se separa de certo valor ideológico, em geral implícito nos pronunciamentos oficiais e documentos históricos. ${ }^{7}$ Do ponto de vista ideológico, a defesa do uso de evidências na política é, entre outras coisas, uma tentativa de legitimação da plataforma do governo Tony Blair frente ao eleitorado e um instrumento a mais nas lutas pelo poder político de certos segmentos da burocracia pública britânica.

O segundo passo da construção do nosso método de análise consiste na explicitação dos pressupostos epistemológicos dos modelos subjacentes às PPBEs. Tais pressupostos dizem respeito à natureza, à estrutura e ao funcionamento dos processos genericamente "sociais" que subjazem às políticas públicas. Cientistas sociais em geral (economistas, cientistas políticos etc.) e policymakers servem-se de modelos através dos quais se "enxergam”, concebem e interpretam as políticas públicas. Com este artifício, seremos capazes de descrever de forma estilizada o processo decisório de um policymaker e o papel das evidências nesse processo.

Este segundo passo metodológico se conecta ao primeiro (análise histórica), pois a história das PPBEs nos dá pistas sobre os pressupostos epistemológicos que, por assim dizer, emolduram o conceito de evidência. Ora, é possível interpretar essa história como uma "dialética" entre dois modelos gerais: i) racionalista: herdeiro de uma visão filosófica clássica de cunho empirista, iluminista, racionalista, positivista e utilitarista, esse modelo pressupóe que os processos sociais e políticos sejam mecânicos, comparáveis e quantificáveis, e que as decisóes do policymaker sejam puramente racionais, de um tipo de racionalidade instrumental; e ii) construtivista: encara os processos sociais e políticos como "construídos" pela interação entre agentes em suas disputas por poder; as decisóes são aqui concebidas como tomadas em um ambiente de incerteza radical, e as políticas públicas são artifícios sempre sujeitos a interpretação. ${ }^{8}$

Obviamente, os modelos tais como descritos acima são tipos ideais, de sorte que não devemos esperar encontrá-los nas análises e práticas concretas de políticas públicas. Eles marcam os pontos extremos de um continuum, que pode abrigar um número indefinido de modelos intermediários -

7. Neste texto, baseado em Thompson (2000), entende-se por ideologia o modo como os símbolos, principalmente linguísticos, são usados pelos atores sociais, a fim de criarem ou manterem uma assimetria de poder que lhes seja favorável. É neste sentido que Davies (2004, p. 5) afirma que as PPBEs podem ser vistas "como uma ideologia política, representando um posicionamento em defesa da demonstração empírica, além de abordagens mais teóricas ao discurso e à ação política". Phillip Davies, o autor desta citação, era chefe do Social Researcher's Office unidade pertencente ao Gabinete do primeiro-ministro do Reino Unido - à época do surgimento das PPBEs como um movimento defendido em documentos oficiais do governo britânico.

8. Este artigo segue a caracterização do construtivismo ou construcionismo de Lejano (2006). 
estes sim, mais realistas -, que mesclam os pressupostos racionalistas e construtivistas de muitas formas diferentes. ${ }^{9}$

Há uma relação entre a forma como se concebem os processos socioeconômicos sobre os quais incidem as políticas públicas, por um lado, e o modo como se definem, usam e ranqueiam as evidências empregadas na tomada de decisóes pelos policymakers, por outro. Se tais processos forem concebidos como predominantemente racionais, em que seus componentes e mecanismos sejam claros e suas açóes previsíveis, então as evidências privilegiadas para apoiar a tomada de decisóes terão como padróes os dados empíricos que funcionarão como inputs de modelos quantitativos, à maneira daqueles usados nas ciências naturais. Contudo, se a realidade social sobre a qual atuam as políticas públicas for concebida como um processo principalmente interativo entre agentes, cujas decisóes e motivaçóes não são claras, tampouco previsíveis, entấo o leque de evidências potencialmente empregáveis em políticas públicas se amplia bastante, abrangendo até elementos subjetivos como crenças, juízos e valores pessoais. $\mathrm{O}$ modo como os pressupostos epistemológicos são caracterizados num dado modelo é que vai determinar a extensão do conceito de evidência a ser utilizado.

O terceiro passo metodológico consiste em enfocar os contextos de uso das evidências pelos agentes públicos (burocratas, policymakers, implementadores) envolvidos nas políticas públicas. Esse passo radica no pragmatismo filosófico norte-americano (por exemplo, Peirce (1905)) e, mais especificamente, na filosofia da linguagem do chamado "segundo" Wittgenstein (1979), para quem "significado é uso". Ou seja, assim como os contextos de uso das expressóes linguísticas são fundamentais na determinação dos significados destas, os contextos em que as evidências são usadas nas decisóes em políticas públicas dirão muito acerca dos modos como o conceito de evidência é aplicado.

Aprofundemos um pouco esse terceiro passo metodológico. Quem fala em contextos concretos de uso de um termo ou conceito, fala em casos particulares - ou seja, exemplos e contraexemplos (reais ou hipotéticos) -, mas, acima de tudo, fala num "mergulho" na experiência concreta dos usuários desse termo ou conceito. Neste quesito, os estudos empíricos, baseados em surveys de alcances nacionais e internacionais, podem ser usados como parte do esforço de elucidação conceitual. De fato, aqueles estudos não apenas ilustram o assunto, mas servem também como fontes de insights sobre as possiblidades do conceito de evidência - seus usos, aplicaçôes, dimensóes, críticas -, com base em experiências reais e vividas por policymakers e outros atores sociais. ${ }^{10}$

\section{MODELO MODERADO DE POLÍTICAS PÚBLICAS}

O tipo de instrumento informativo, bem como o seu modo de uso pelo agente de uma política pública, dependerá da forma como este agente concebe a realidade social sobre a qual atua. Esta forma de conceber, esta interpretaçáo ou representação da realidade, é o que chamamos aqui de

9. A ideia básica desse continuum, devo-a a Marston e Watts (2003). Nilsson et al. (2008, p. 343-344) também se servem dessa ideia, em um contexto diferente do usado no presente artigo. Além disso, convém advertir que não se autoriza neste texto qualquer identificação dos modelos aqui chamados de "racionalista" e "construtivista" com caracterizações de correntes homônimas nas várias disciplinas filosóficas e científicas. Por exemplo, não se identifica o modelo racionalista com o racionalismo filosófico do século XVII (Descartes, Espinosa, Leibniz, por exemplo), nem o modelo construtivista com o construtivismo pedagógico de Jean Piaget.

10. Os estudos mostram que o leque de possibilidades de uso das evidências é muito amplo, podendo ir desde o simples uso "instrumental" ou "técnico" para a escolha deste ou daquele curso de ação numa política, até o uso "simbólico" na construção de narrativas convincentes em favor de ações cujos propósitos, frequentemente velados, são de luta por poder. Ver, entre outros, Amara, Ouimet e Landry (2004) e Stevens (2011). 
modelo. ${ }^{11}$ Uma visão da realidade social filtrada por um modelo mais racionalista levará a um uso mais técnico, impessoal e instrumental das evidências, nas quais se destacaráo os dados empíricos quantitativos e passíveis de modelagem estatística. Em contraposição, uma visão mais construtivista da realidade social, com ênfase na capacidade criativa e interpretativa dos atores sociais, acarretará um uso mais amplo de instrumentos informativos, inclusive aqueles mais pessoais e menos objetivos.

Quanto mais racionalista for o modelo, mais tenderá a desconsiderar a complexidade inerente à dinâmica das decisões políticas. Entre os fatores dessa complexidade, estão a não linearidade das decisôes, sua multicausalidade, suas condiçôes de incerteza, bem como a influência de crenças, hábitos, tradiçóes, emoções, valores, ideologia e interesses nas açôes e escolhas em políticas públicas. Por seu turno, quanto mais o agente político se apoiar em pressupostos construtivistas radicais, menos será possível fazerem-se enunciados gerais sobre os comportamentos dos agentes econômicos, políticos e sociais. Assim, em última instância, o construtivismo extremo inviabiliza a análise e avaliação de políticas públicas, assim como o papel das evidências, pois o processo gerador das políticas - as intençóes dos atores - é interpretado como obscuro, talvez incognoscível.

Diante das falhas dos modelos racionalista e construtivista puros, anteriormente apontadas, propóe-se um modelo moderado, que fuja aos extremos e preserve um espaço de racionalidade para a cognição dos processos sociais e de políticas públicas, conciliando isso com a açáo consequente dos implementadores de políticas públicas. Esse modelo terá os seguintes pressupostos epistemológicos fundamentais: P1) apreender o social, o econômico e o político como sistemas complexos, porém racionalmente analisáveis; P2) considerar os limites do conhecimento em geral, a falibilidade do conhecimento científico e as especificidades do conhecimento em ciências sociais; P3) considerar o status epistemológico (científico) da disciplina ou área de política sob questão; e P4) entender o uso das evidências dentro de uma estrutura geral de ação do policymaker ou de outros stakeholders (conforme o caso), a qual, por sua vez, se especifica dentro de uma moldura contextual. Detenhamo-nos brevemente sobre cada um destes pressupostos.

Em relação ao item P1, sistemas complexos são sistemas abertos - isto é, com interaçóes com o ambiente circundante - constituídos de muitas variáveis cujas relaçóes são não lineares. Outras propriedades possíveis de sistemas complexos são: auto-organização, multidimensionalidade, capacidade de operar fora de um equilíbrio e sensibilidade a contextos históricos. ${ }^{12}$

Quanto ao segundo pressuposto fundamental, ao contrário do que poderia supor um racionalismo extremo, o modelo moderado pressupóe que o conhecimento das realidades sobre as quais atua o poder público náo seja exato, tampouco infalível. Ao invés disso, tal conhecimento compóe-se de "conjecturas", para as quais é recomendável moderação nas explicaçóes e inferências causais. Além disso, o modelo moderado considera certos traços específicos ao conhecimento social, tais como sua contingência histórica e sua reflexividade (os atores são sujeitos e objetos do

11. Um modelo pode ter vários graus de explicitação ou articulação analítica por parte do agente que dele faz uso. Neste artigo, destaca-se que os modelos de sociedade e decisões políticas usados pelos policymakers permanecem, na maioria das vezes, implícitos ou subjacentes às decisões de políticas públicas. Não obstante o seu caráter latente e pré-analítico, esses modelos servem como referências de fundo para as ações práticas das autoridades de políticas. Esse conceito de modelo aproxima-se dos conceitos de ideologia, conforme expressos nas obras de Schumpeter (1964), Dobb (1973) e Robinson (1979). Agradeço a um(a) parecerista por chamar-me a atenção para essa semelhança conceitual. 12. Autores como Cilliers (1998), Cooksey (2001) e Cloete (2006) estudaram os sistemas complexos e defendem sua aplicabilidade a vários tipos de sistemas administrativos, econômicos, políticos, legais e sociais. 
conhecimento social). Isso reforça a necessidade de se delimitarem bem as condiçóes de validade dos conhecimentos usados nas decisóes de políticas públicas.

O pressuposto epistemológico fundamental P3 reza que as políticas públicas atuam sobre campos do saber muito variados - resultado da complexidade das realidades subjacentes a esses campos -, com igualmente variados graus de consolidação epistemológica. Há áreas de políticas com sólidos núcleos teóricos e metodológicos, tais como as áreas de saúde e macroeconomia. ${ }^{13}$ Mas existem também áreas em que não há uma base evidencial tão sólida, não se sabendo ao certo o que funciona ou não em termos de políticas públicas (exemplos: privacidade na internet e novas formas de governança). O modelo moderado deve respeitar essas diferenças e assumir que as decisóes dos policymakers poderão ser racionalmente tomadas, segundo diversos graus de rigor metodológico, conforme o nível de consolidação epistemológica do campo ou da área de política em que se esteja atuando.

Há certos corolários dos mencionados pressupostos fundamentais, especificamente no que se refere ao uso das evidências, que compóem igualmente o modelo moderado: C1) a relevância de análises conceituais e abordagens teóricas - principalmente nas áreas menos consolidadas (do pressuposto P3), é fundamental haver um trabalho prévio de análise conceitual e construçáo de teorias; C2) o papel elucidativo das evidências - ao invés de serem instrumentos "neutros" de informaçóes para a tomada de decisóes (segundo um modelo de racionalidade instrumental), as evidências terão mais o papel de esclarecer os problemas envolvidos nas tomadas de decisóes (dos pressupostos P1 e P2); ${ }^{14}$ C3) a diversidade dos conhecimentos e evidências: o modelo moderado deve conter um escopo largo acerca do que se pode entender por evidência, mostrando sensibilidade a diversos tipos e usos do conhecimento (dos pressupostos P1, P3 e P4); e C4) ouvir os atores interessados - consideram-se os stakeholders, participantes das diversas etapas ou segmentos das políticas públicas, como potenciais fontes de informaçóes e evidências, e não apenas os pesquisadores, técnicos do governo e experts (dos pressupostos P1, P3 e P4).

Para fechar esta seção, uma advertência. Não se busca descartar pura e simplesmente os modelos racionalista e construtivista, mas aproveitar algumas de suas ideias e, incorporando outras molduras conceituais - por exemplo, fornecidas pelo pragmatismo e por Wittgenstein (1979) -, obter-se uma abordagem analítica mais robusta para as políticas públicas. Portanto, chamo o modelo aqui proposto de "moderado" não apenas porque ele pretende situar-se a meio caminho entre os modelos racionalista e construtivista, buscando um salutar meio-termo entre ambos, mas também porque o modelo moderado é acima de tudo crítico, ao reconhecer os limites do conhecimento, e pragmático em relação ao contexto de ação do agente público. Este último aspecto, que "dialoga"

13. 0 conceito de "consolidação epistemológica" de uma disciplina científica é relativo e comparativo às áreas de políticas públicas. Em tese, todas as áreas podem ter o seu grau de "estabelecimento epistemológico" questionado. Por exemplo, os protocolos de atuação em macroeconomia têm mudado ao longo da história. Sobre isso, ver as críticas de economistas como Blanchard, Dell'Ariccia e Mauro (2010), em relação ao receituário da política macroeconômica dominante, o qual teria sido em grande parte ineficaz para evitar e tratar os efeitos da crise mundial de fins dos anos 2000. Outros, como Romer (2016) e Reis (2017) têm feito uma crítica mais extensa e radical à macroeconomia, incluindo aspectos como as relações de causalidade, a pesquisa, a política, as previsões e o ensino nessa disciplina. Mas, numa análise comparativa - é isto o que se deseja salientar neste texto -, há disciplinas mais bem estabelecidas epistemologicamente que outras. Por isso, e a despeito dos questionamentos epistemológicos que sempre surgirão em cada área, não vejo razão para se desconfiar que a macroeconomia e a saúde sejam das áreas de políticas públicas mais avançadas nesse particular.

14. Esse corolário sugere que, talvez, seja mais apropriado falar-se de políticas públicas "informadas" por evidências (PPIEs) do que "baseadas" em evidências. PPIEs - expressão também usada na literatura especializada - faria mais jus ao caráter elucidativo dos problemas subjacentes à tomada de decisões pelos policymakers. Essas decisões podem abranger tanto a utilização de evidências para construir diagnósticos situacionais quanto para intervir na realidade, permitindo ao agente público optar por este ou aquele caminho de política pública. 
com o pressuposto epistemológico P4 do modelo (entender o uso das evidências dentro de uma estrutura geral de ação do policymaker), será analisado mais pormenorizadamente na próxima seção.

\section{ESTRUTURA DA AÇÃO DO POLICYMAKER}

A história das PPBEs sinaliza o papel das evidências como meios para a consecução de propósitos públicos de bem-estar, por meio da provisão de serviços públicos (Solesbury, 2001). No entanto, estas têm sido usadas de muitas maneiras e com propósitos diferentes, para além das finalidades de bem-estar geral ou do interesse público, como quer que se definam estes estados. Frequentemente, o uso das evidências obedece a critérios que pouco têm a ver com a eficiência, eficácia e efetividade das políticas, servindo, no lugar disso, de instrumentos simbólicos de poder político, defesa de posiçóes ideológicas e manutenção do status de certas carreiras da burocracia pública.

$\mathrm{O}$ que se disse no parágrafo anterior fundamenta a necessidade de se entender o uso das evidências dentro de um modelo geral ou estrutura das açóes (decisóes) em políticas públicas. As evidências desempenham o papel de meios informativos para a tomada de decisóes em políticas públicas. Essas informaçóes, por sua vez, podem ser obtidas por diversas outras formas, de técnicas específicas a teorias, conceitos, modelos, disciplinas etc. ${ }^{15}$

A estrutura da ação engloba quatro elementos: i) o agente; ii) seu acervo de crenças, conhecimentos, preferências, valores, habilidades e capacidades; iii) os propósitos; e iv) os meios usados pelo agente para atingir seus fins. Essa estrutura não se dá num "vácuo ontológico", mas ganha sentido apenas num pano de fundo delimitado por uma moldura contextual.

Há, contudo, inúmeras maneiras de se descrever o contexto de uma ação ou decisão de um agente público engajado numa política pública, especificamente no que se refere ao uso das informaçóes (evidências). Isso porque o contexto, por definição, remete a estados de coisas particulares, concretos e, na questáo que nos interessa no momento, refere-se a estados de coisas experienciados e vividos pelos policymakers. Propóem-se neste artigo três categorias de fatores constituintes do referido contexto, aqui chamado tecnicamente de moldura contextual: i) políticos - a temporalidade da política, compromissos ideológicos, disputas por poder, democracia; ii) epistemológicos - avaliação da política, incerteza, reflexividade do conhecimento social etc. (Mulgan, 2005, p. 224); e iii) normativos, institucionais e organizacionais. Os supracitados tipos de fatores se entretecem numa trama complexa.

De acordo com o modo como se define a moldura contextual, as evidências usadas para informar as decisões dos agentes nas políticas públicas definem-se desta ou daquela forma, ganham esta ou aquela feição. De fato, na abordagem das PPBEs proposta neste texto, as evidências são quaisquer instrumentos informativos usados pelos agentes públicos em suas decisóes de políticas públicas, dada uma moldura contextual.

Um exemplo intuitivo ajudará a clarificar o papel da moldura contextual na definição do conceito de evidência. Seja um analista ou policymaker que busca atuar sobre o comportamento da dívida pública de um país. Ele forma suas convicçóes e subsidia suas decisóes com base, suponhamos,

15. A distinção conceitual entre evidências (meios ou instrumentos informacionais, com conteúdo de informação) e as formas de obtenção de evidências (métodos, técnicas, fontes, molduras analíticas etc.) permite-nos introduzir novas classificações e tipologias, as quais poderão vir a ser úteis em futuros trabalhos mais aplicados. Por exemplo, se, na obtenção de evidências, forem aplicados métodos sistematizados e reprodutíveis, elas poderão ser qualificadas como "científicas"; se forem oriundas de registros administrativos mantidos pela administração pública, sem aplicação de métodos sistematizados e reprodutíveis, poderão ser qualificadas, talvez, como "técnicas". Agradeço a um(a) parecerista por alertar-me para essa possibilidade classificatória. 
em informaçóes obtidas pelo uso de modelos contábeis ou econométricos de comportamento da dívida. Em um primeiro cenário, tem-se um clima político-econômico favorável, ensejando a uma estabilidade dos parâmetros do modelo (câmbio, juros, produto interno bruto - PIB etc.), levando o policymaker à confiança nos resultados das simulaçóes e à não alteração da política de administração da dívida pública. Em um segundo cenário, há uma crise política que gera incerteza quanto aos mesmos parâmetros, levando o agente a confiar menos nos resultados de seu modelo - que trabalha com parâmetros fixos - e a buscar complementá-los com opiniôes de autoridades, agentes do mercado e experts em política fiscal. Neste segundo cenário, o policymaker em questão será levado a evitar publicar os resultados mais "pessimistas" de suas análises, temendo talvez um agravamento do quadro de estresse do mercado e do estado de confiança keynesiano da economia. Embora possa fazer correçóes pontuais na gestão da dívida, ele evitará mudanças drásticas e repentinas, visando minimizar o risco de especulação financeira e de insustentabilidade ou de deterioração da qualidade da dívida.

No exemplo anterior, os cenários primeiro e segundo (favorável e desfavorável, respectivamente) compóem molduras contextuais diferentes para a estrutura da açáo do policymaker. Consequentemente, são distintas as evidências usadas para subsidiar suas decisóes acerca da política pública em questão. Nota-se que os fatores políticos - possíveis reaçóes do mercado que desestabilizem a economia e, por conseguinte, abalem o apoio do eleitorado e do Congresso ao governo - e as fontes de informaçóes menos objetivas (opinióes pessoais, feelings) têm mais proeminência no segundo cenário.

O exemplo acima também sugere que os aspectos epistemológicos - ligados à cognição, ao diagnóstico da situação - e políticos (decisóes que afetam o perfil de poder entre os agentes) interagem. No cenário "de estresse", o conhecimento do curso futuro da dívida pública tornou-se mais incerto e menos provável, em razão de uma crise política. Neste caso, a decisão do gestor da dívida levará em conta a formaçáo de juízos sobre as decisóes de outros agentes (mercado, grupos potencialmente geradores de passivos contingentes para o governo etc.), para as quais podem concorrer motivações políticas.

\section{CONSIDERAÇÕES FINAIS}

A epígrafe deste artigo reproduz palavras de Keynes citadas com frequência nos estudos sobre PPBEs. Ela diz o seguinte: "não há nada que um governo deteste mais do que estar bem informado, pois isto torna o processo de tomada de decisóes muito mais complicado e difícil" (Skidelsky, 1992). A despeito do contexto em que foi proferida, não se pode deixar de notar seu tom irônico: os governos "detestam" a informação, porque esta os compele a um esforço raciocinativo e justificatório para tomarem suas decisóes. Quanto mais informação, maior tende a ser esse esforço, pois, desde Sócrates, sabe-se que, quanto mais alguém acumula conhecimento, mais tem consciência da própria ignorância. Vale dizer, em qualquer área do saber e, em particular, no processo de decisão pública, o fluxo de novas perguntas tende a ultrapassar o estoque de coisas sabidas. Por sua vez, se a epígrafe que abre este artigo for tomada ao pé da letra, entáo será historicamente falsa: tanto os governos do passado quanto os atuais, tanto em regimes democráticos quanto ditatoriais, jamais detestaram as informaçóes; ao contrário, os governos sempre as "amaram", pelo poder que elas lhes trazem.

Keynes já notara as complicadas relaçóes entre as informações e as decisóes dos policymakers. Este artigo procurou contribuir para melhorar o entendimento dessas relaçóes, fornecendo um método de análise conceitual sobre as evidências usadas em políticas públicas. A análise fornece razóes 
para pensar que a elucidação do conceito de evidência não se pode dar sem a delimitação de um modelo moderado, de caráter pragmático e realista, cujos pressupostos epistemológicos reconheçam o caráter ao mesmo tempo complexo e racionalizável dos processos sociais sobre os quais incidem as decisóes públicas. Os pressupostos desse modelo também recomendam atenção aos limites do conhecimento social e aos diferentes graus de consolidação epistemológica das áreas de política. Como corolário, o modelo se abre à consideração de uma ampla gama de tipos, fontes, métodos e técnicas de evidências, inclusive as produzidas pelos diversos stakeholders no processo da política pública em questão. De forma alguma o modelo moderado reduz o significado de "evidência" ao de "evidência científica” (ver a nota de rodapé n. 2).

O modelo defendido neste estudo situa-se numa posição crítica a uma visão tradicional das PPBEs, segundo a qual as evidências são instrumentos mais ou menos "neutros" de tomada de decisão nas políticas públicas - inclusive do ponto de vista político-ideológico -, como se aquelas fossem parâmetros externos ou "constantes" do modelo. ${ }^{16}$ Contra essa interpretação, argumentamos que o modo como as evidências são definidas e usadas é indissociável de como se encara a natureza dos processos sociais e decisórios de políticas públicas - o que depende, por sua vez, de certos pressupostos epistemológicos e de uma estrutura de ação ou decisão, que só faz sentido dentro de uma moldura contextual.

Parte importante da elucidação empreendida neste texto é devotada a esboçar a referida moldura contextual, ao mesmo tempo em que se procura mostrar, por meio de exemplos, como essa moldura pode definir as evidências e seus usos. Sem pretender fornecer uma lista exaustiva, propóe-se que os fatores constitutivos dessa moldura sejam de ordem epistemológica, política, legal-institucional e organizacional. Como um cenário ou pano de fundo de uma cena teatral, a moldura contextual constitui uma unidade que sugere determinados tipos de ação, bem como o uso de determinados tipos de instrumentos ou evidências. Assim como os elementos dramáticos e pictóricos de uma cena teatral não se separam no desenrolar da peça, os elementos epistemológicos e políticos (além dos de outras ordens) náo se separam no contexto de decisão do agente público. Como o exemplo do gestor da dívida pública (seção 4) pretende ter deixado claro, o uso político, simbólico ou ideológico das evidências - tipos de uso corroborados por vários estudos empíricos e pela própria história das PPBEs - é parte constitutiva do conceito de evidência.

$\mathrm{Na}$ mencionada visão tradicional acerca das PPBEs, a arte das políticas públicas se resume numa espécie de cálculo técnico da efetividade e custo de um conjunto bem definido de opçóes de política (Marston e Watts, 2003, p. 158). Essa perspectiva parece encarar as políticas públicas como uma espécie de ciência idealizada, capaz de descobrir as respostas certas aos problemas humanos. Ora, em políticas públicas, dificilmente seria possível separar-se arte de ciência, fatos de valores, conhecimento de política. ${ }^{17}$ Paradoxalmente, a visão tradicional - cuja propaganda oficial declara ser isenta de ideologia e de política - aumenta o risco de que as PPBEs se transformem num meio ideológico para as elites políticas, ou para certos segmentos tecnocráticos incrustados na burocracia

16. Esta interpretação tradicional das PPBEs, ora criticada, reflete-se nas definições de Plewis (2000) e Davies (2004) citadas na introdução deste artigo, e é magistralmente ilustrada pelo discurso do líder do Partido Trabalhista Australiano, Mark Latham, em 2001 (citado em Marston e Watts, 2003, p. 149-150): "Os mitos do welfare state estão baseados em velhas formas ideológicas de pensar, uma luta entre as políticas pró-governo e pró-mercado. Está claro agora que ambas as abordagens são falhas. 0 mundo mudou. Os promotores do bem-estar precisam olhar para além da velha esquerda e da nova direita, em direção às políticas baseadas em evidências, que podem pôr fim à tragédia humana da pobreza".

17. Para uma crítica consistente da velha dicotomia filosófica entre fatos e valores, com aplicações à teoria do desenvolvimento, ver Putnam (2002). 
pública, imporem a sua perspectiva, ao conjunto da sociedade, acerca de quais são os problemas sociais relevantes e suas soluçóes. Desse modo, desvalorizam-se outras formas de conhecimento, práticas sapienciais, juízos profissionais e as vozes dos cidadãos comuns.

\section{REFERÊNCIAS}

AMARA, N.; OUIMET, M.; LANDRY, R. New evidence on instrumental, conceptual, and symbolic utilization of university research in government agencies. Science Communication, v. 26, n. 1, p. 75-106, Sept. 2004.

BLANCHARD, O.; DELL'ARICCIA, G.; MAURO, P. Rethinking macroeconomic policy. Washington: International Monetary Fund, Feb. 2010.

CILLIERS, P. Complexity and postmodernism. Routledge: London, 1998.

CLOETE, F. Chaos and quantum complexity approaches to public administration and management: insights from the 'new sciences'. Administratio Publica, v. 14, n. 1, p. 45-83, July 2006.

COOKSEY, R. W. What is complexity science? Emergence, v. 3, n. 1, p. 7-103, 2001.

DAVIES, P. Is evidence-based government possible? London: Jerry Lee Lecture, 2004.

DOBB, M. Teorias do valor e distribuição desde Adam Smith. Lisboa: Presença, 1973.

LEJANO, R. P. Frameworks for policy analysis: merging text and context. New York: Routledge, 2006.

MARSTON, G.; WATTS, R. Tampering with evidence: a critical appraisal of evidence-based policy-making. The Drawing Board: an Australian Review of Public Affairs, v. 3, n. 3, p. 143-163, 2003.

NILSSON, M. et al. The use and non-use of policy appraisal tools in public policy making: an analysis of three European countries and the European Union. Policy Sciences, v. 41, n. 4, p. 335-355, 2008.

NUTLEY, S. Bridging the policy-research divide: reflections and lessons from UK. In: NATIONAL INSTITUTE OF GOVERNANCE CONFERENCE, Canberra, Australia, Apr. 2003. Canberra: [s.n.], Apr. 2003.

OLIVER, K. et al. A systematic review of barriers to and facilitators of the use of evidence by policymakers. BMC Health Services Research, v. 14, n. 2, 2014. Disponível em: <http://www. biomedcentral.com/1472-6963/14/2>.

PEIRCE, C. S. What pragmatism is. The Monist, v. 15, n. 2, p. 161-181, Apr. 1905.

PINHEIRO, M. M. S. Políticas públicas baseadas em evidências: delimitando o problema conceitual. Brasília: Ipea, 2020.

PLEWIS, I. Educational inequalities and education action zones. In: PANTAZIS, C.; GORDON, D. (Ed.). Tackling inequalities: where are we now and what can be done? Bristol: Policy Press, 2000.

PUTNAM, H. The collapse of the fact/value dichotomy and other essays. Cambridge: Harvard University Press, 2002. 
REIS, R. Is something really wrong with macroeconomics? London: CESifo, 2017.

ROBINSON, J. Filosofia econômica. Rio de Janeiro: Zahar, 1979.

ROMER, P. The trouble with macroeconomics. New York: Commons Memorial Lecture of the Omicron Delta Epsilon Society, 2016. Mimeografado.

SCHUMPETER, J. A. História da análise econômica. Rio de Janeiro: Fondo de Cultura, 1964.

SHADISH JUNIOR, W; COOK, T.; LEVITON, L. Foundations of program evaluation: theories of practice. Newbury Park: Sage Publications, 1995.

SKIDELSKY R. John Maynard Keynes: a biography. The economist as saviour, 1920-1937. London: Macmillan; 1992. v. 2.

SOLESBURY, W. Evidence based policy: whence it came and where it's going. London: ESRC UK Centre for Evidence Based Policy and Practice, Oct. 2001.

STEVENS, A. Telling policy stories: an ethnographic study of the use of evidence in policy-making in the UK. Journal of Social Policy, v. 40, n. 2, p. 237-255, Apr. 2011.

STRUNZ, S. Is conceptual vagueness an asset? Arguments from philosophy of science applied to the concept of resilience. Ecological Economics, v. 76, p. 112-118, 2012.

THOMPSON, J. B. Ideologia e cultura moderna: teoria social crítica na era dos meios de comunicação de massa. 6. ed. Petrópolis: Editora Vozes, 2000.

UNITED KINGDOM. Cabinet Office. Modernising government white paper. London: Centre for Management and Policy Studies, 1999. Disponível em: <https://bit.ly/38mfYfK>. Acesso em: 27 jun. 2019.

WITTGENSTEIN, L. Investigaçóes filosóficas. 2. ed. São Paulo: Abril Cultural, 1979.

WORTHEN, B.; FITZPATRICK, J.; SANDERS, J. Avaliação de programas: concepções e prática. São Paulo: Editora Gente, 2004. 
